OPEN

SUBJECT AREAS:

SUSTAINABILITY

ENVIRONMENTAL SCIENCES

NANOTECHNOLOGY

MATERIALS SCIENCE

Received

30 May 2012

Accepted

27 July 2012

Published

23 August 2012

Correspondence and requests for materials should be addressed to

J.-M.Y. (junminyan@

jlu.edu.cn) or Q.J.

(jiangq@jlu.edu.cn)

\section{Pd/C Synthesized with Citric Acid: An Efficient Catalyst for Hydrogen Generation from Formic Acid/Sodium} Formate

\author{
Zhi-Li Wang, Jun-Min Yan, Hong-Li Wang, Yun Ping \& Qing Jiang
}

Key Laboratory of Automobile Materials, Ministry of Education, Department of Materials Science and Engineering, Jilin University, Changchun 130022, China.

A highly efficient hydrogen generation from formic acid/sodium formate aqueous solution catalyzed by in situ synthesized $\mathrm{Pd} / \mathrm{C}$ with citric acid has been successfully achieved at room temperature. Interestingly, the presence of citric acid during the formation and growth of the Pd nanoparticles on carbon can drastically enhance the catalytic property of the resulted $\mathrm{Pd} / \mathrm{C}$, on which the conversion and turnover frequency for decomposition of formic acid/sodium formate system can reach the highest values ever reported of $85 \%$ within 160 min and $64 \mathrm{~mol} \mathrm{H}_{2} \mathrm{~mol}^{-1}$ catalyst $\mathrm{h}^{-1}$, respectively, at room temperature. The present simple, low cost, but highly efficient $\mathrm{CO}$-free hydrogen generation system at room temperature is believed to greatly promote the practical application of formic acid system on fuel cells.

ydrogen $\left(\mathrm{H}_{2}\right)$, a sustainable and environmentally attractive energy carrier, is now widely regarded to has the potential to play a major role in high-efficiency power generation systems, including polymer electrolyte membrane (PEM) fuel cell, in the future ${ }^{1,2}$. However, secure generation and storage of $\mathrm{H}_{2}$ remain as the insufficiently solved problems toward the $\mathrm{H}_{2}$ energy based economy ${ }^{3}$. Methods for $\mathrm{H}_{2}$ storage, such as highpressure gas containers, cryogenic liquid/gas containers, solid metal hydrides, carbon nanotubes, and metalorganic frameworks, are suffering from more or less obstacles in safety (high pressure or low temperature are needed) and efficiency (low volumetric and gravimetric densities of $\left.\mathrm{H}_{2}\right)^{1,4-6}$. Consequently, $\mathrm{H}_{2}$ stored in some stable chemical compounds is then desired ${ }^{7-9}$.

Recently, formic acid $\left(\mathrm{FA}, \mathrm{HCO}_{2} \mathrm{H}\right)$, a major product of biomass process, has attracted a great of research interests in $\mathrm{H}_{2}$ storage due to its high energy density, excellent stability, and non-toxicity at room temperature ${ }^{7,10-12}$. FA can be catalytically decomposed to $\mathrm{H}_{2}$ and carbon dioxide $\left(\mathrm{CO}_{2}\right)$ via a dehydrogenation reaction ${ }^{13}$ :

$$
\mathrm{HCO}_{2} \mathrm{H}(\mathrm{l})=\mathrm{H}_{2}(\mathrm{~g})+\mathrm{CO}_{2}(\mathrm{~g}) \quad \Delta \mathrm{G}_{298 \mathrm{k}}=-35.0 \mathrm{KJ} \mathrm{mol}^{-1}
$$

However, carbon monoxide (CO), which is a fatal poison to catalysts of fuel cell ${ }^{14,15}$, can also be generated through another undesirable dehydration pathway ${ }^{13}$ :

$$
\mathrm{HCO}_{2} \mathrm{H}(\mathrm{l})=\mathrm{H}_{2} \mathrm{O}(\mathrm{l})+\mathrm{CO}(\mathrm{g}) \quad \Delta \mathrm{G}_{298 \mathrm{k}}=-14.9 \mathrm{KJ} \mathrm{mol}^{-1}
$$

The reaction pathway depends on the catalyst, and the reaction condition including temperature and $\mathrm{pH}$ value of the reaction system ${ }^{7}$.

It is reported that FA can be selectively dehydrogenated without CO generation by homogeneous catalysis at near-ambient temperature ${ }^{4,16-19}$. Nevertheless, homogeneous catalysts unavoidably lead to the difficulties in separating, controlling and recycling the catalysts in the reaction systems ${ }^{20}$. Therefore, heterogeneous catalysis nowadays attracts tremendous research interests ${ }^{21-30}$. For $\mathrm{H}_{2}$ generation from FA system, Pd nanoparticles (NPs) are found to be more efficient than other monometallic $\mathrm{NPs}^{23,27}$, although their catalytic activities and selectivities are still very poor even at elevated temperature up to $365 \mathrm{~K}^{23,26}$. The current methods for improving the dehydrogenation performance of FA are mainly focused on application of bi/tri-metallic Pd-based composites, alloys or core-shell nanostructures as the catalysts, in which the incorporation of some other elements, such as $\mathrm{Au}, \mathrm{Ag}, \mathrm{Dy}, \mathrm{K}$, etc., can modify the catalytic surface of Pd NPs and then result in the higher activities and 


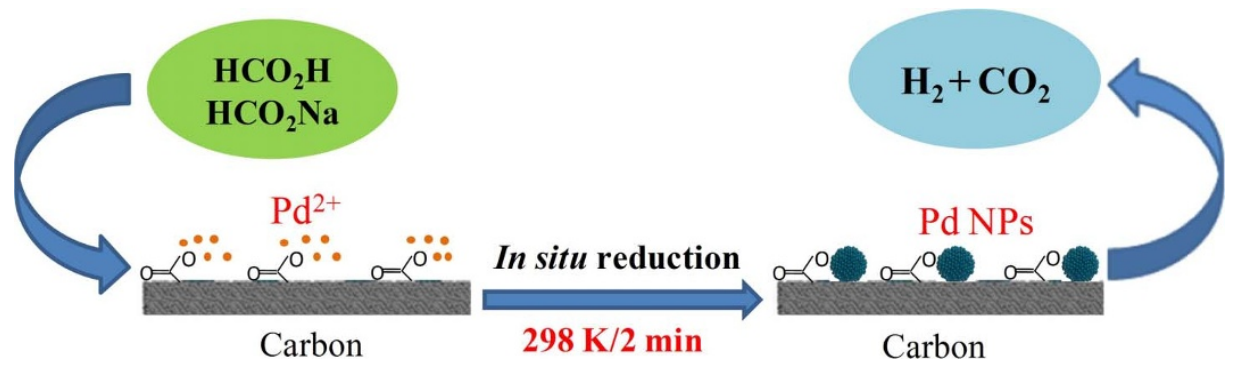

Figure 1 Experimental design. Schematic illustration for $\mathrm{H}_{2}$ generation from FA/SF catalyzed by in situ prepared Pd/C with citric acid at $298 \mathrm{~K}$.

selectivities ${ }^{23,26-28,31,32}$. However, most of these catalysts have to work at high temperature ${ }^{23,26,28,31,32}$, and the kinetic property of FA dehydrogenation still needs to be promoted. Moreover, the structural complexities of these polymetallic NPs make their preparations much more complicated and subeconomic than those of monometallic NPs. For instance, multi-step synthetic process, long reaction time, and strict reaction conditions including high temperature, inert gas protection and post-processing are generally required during syntheses of the polymetallic Pd-based catalysts ${ }^{23,26-32}$, which greatly hinders their large-scale practical applications.

During FA dehydrogenation, formate, an intermediate product in FA dehydrogenation ${ }^{24}$, is usually added to promote the activity of catalyst $^{22,23,26,28,29}$. It is reported that sodium formate $\left(\mathrm{SF}, \mathrm{HCO}_{2} \mathrm{Na}\right)$ can liberate $\mathrm{H}_{2}$ through a hydrolysis reaction with some homogenous catalysts $^{33}$ :

$$
\mathrm{HCO}_{2} \mathrm{Na}+\mathrm{H}_{2} \mathrm{O}(\mathrm{l})=\mathrm{H}_{2}(\mathrm{~g})+\mathrm{NaHCO}_{3}
$$

Therefore, if SF could also generate $\mathrm{H}_{2}$ in a heterogamous catalysis system of FA, the efficiency of $\mathrm{H}_{2}$ generation from FA/SF system can be further improved.

In light of the above reason, exploring a facile and low-cost strategy to endow the solid catalyst in a simple structure, such as monometallic catalyst, with excellent activity, selectivity, and stability for $\mathrm{H}_{2}$ generation from both $\mathrm{FA}$ and $\mathrm{SF}$ in aqueous solution at room temperature without $\mathrm{CO}$ contamination is of great interest to meet the demand of on-board fuel cell applications.

Herein, we report the highly efficient $\mathrm{H}_{2}$ generation from FA/SF aqueous solution at $298 \mathrm{~K}$ catalyzed by in situ prepared monometallic $\mathrm{Pd} / \mathrm{C}$ in the presence of citric acid. The key to obtain the excellent catalytic property of $\mathrm{Pd} / \mathrm{C}$ is the modification of citric acid during the formation and growth of the Pd NPs on carbon, which results in the ultrafine and well dispersed Pd NPs with highly active sites on carbon. Moreover, SF in the reaction system plays the important roles as not only the co-catalyst but also the reducing agent and $\mathrm{H}_{2}$ source. This greatly simplifies the catalyst preparation, efficiently increases the activity of catalyst, and successfully improves the efficiency of the $\mathrm{H}_{2}$ generation from FA/SF system.

\section{Results}

$\mathrm{H}_{2}$ generation from FA/SF over Pd/C synthesized with citric acid. The strategy for in situ preparation of $\mathrm{Pd} / \mathrm{C}$ with citric acid and $\mathrm{H}_{2}$ generation from FA/SF is shown in Fig. 1. Typically, $5.0 \mathrm{~mL}$ of aqueous solution containing FA $(1.06 \mathrm{M}), \mathrm{SF}(0.84 \mathrm{M})$ and citric acid $(0.03 \mathrm{M})$ is added into $10.0 \mathrm{~mL}$ of $\mathrm{Na}_{2} \mathrm{PdCl}_{4}\left(4.70 \times 10^{-3} \mathrm{M}\right)$ aqueous solution with $95.0 \mathrm{mg}$ of Vulcan XC-72 carbon at $298 \mathrm{~K}$ in air. $\mathrm{Pd}^{2+}$ cations can be easily reduced to Pd NPs by SF (Supplementary Fig. S1) ${ }^{34}$, and well dispersed on carbon within 2 min. The rapid in situ formed $\mathrm{Pd} / \mathrm{C}$, noticeably, in the presence of citric acid, then serves as an efficient catalyst for $\mathrm{H}_{2}$ generation from FA/SF at $298 \mathrm{~K}$.

After the in situ formation of $\mathrm{Pd} / \mathrm{C}$ with citric acid, continuous gas evolution is observed (Fig. 2a), and only mixture of $\mathrm{H}_{2}$ and $\mathrm{CO}_{2}$ but no $\mathrm{CO}$ has been detected by mass spectrometry (MS) and gas chromatography (GC) analyses (Supplementary Fig. S2-4). This means that the present $\mathrm{Pd} / \mathrm{C}$ with citric acid has a good catalytic selectivity for FA dehydrogenation, which is very important for fuel cell applications ${ }^{35}$. More interestingly, $322 \mathrm{~mL}$ of gas, a large volume far exceeding the theoretical value from FA dehydrogenation $(259 \mathrm{~mL})$, can be generated within $160 \mathrm{~min}$ at $298 \mathrm{~K}$. It is noteworthy that pure citric acid aqueous solution with catalyst of $\mathrm{Pd} / \mathrm{C}$ generates no $\mathrm{H}_{2}$ gas (Supplementary Fig. S6). Thereby, the excess of gas is contributed to $\mathrm{H}_{2}$ generation from hydrolysis of SF in this system. Thus, SF, which is usually used as a catalyst promoter (with negligible $\mathrm{H}_{2}$ generation) for FA dehydrogenation, can also act as the $\mathrm{H}_{2}$ source in the present system. Namely, the in situ synthesized heterogeneous $\mathrm{Pd} / \mathrm{C}$ with citric acid has a remarkably high activity to both FA dehydrogenation and hydrolysis of SF for $\mathrm{H}_{2}$ generation.

It is reported that adsorption of water on the surface of catalyst might lead to the deactivation of catalyst in FA dehydrogenation at $333 \mathrm{~K}^{13}$. In this sense, to check if such deactivation from water exists in the present $\mathrm{Pd} / \mathrm{C}$ catalyst, the solvent (water) is substituted by tetrahydrofuran (THF). As a result, no gas has been generated even after reaction for $300 \mathrm{~min}$ (Supplementary Fig. S5). Thus, water in the present system does not inhibit but plays an important role in the highly efficient decomposition of FA/SF. On the other hand, it has been found that, at the elevated reaction temperature, catalysts for FA and formate decomposition always lose their initially good activity within a short period ${ }^{23,36}$. This may be explained by the facts that, at the elevated temperature, $\mathrm{CO}$ is easier to be generated to poison the nanocatalyst ${ }^{4,23}$, and the stability of the nanocatalyst in its size, distribution, and structure is decreased as well ${ }^{37}$. Therefore, the present reaction temperature $(298 \mathrm{~K})$ may be one of the important reason accounting for the low-deactivation of the present $\mathrm{Pd} / \mathrm{C}$ catalyst during $160 \mathrm{~min}$ (Fig. 2a).

Considering the gas generated from FA/SF, the theoretical molar ratio of $\mathrm{H}_{2}: \mathrm{CO}_{2}$ (Supplementary Eq. S3) should be 1.80 : 1 . However, the measured value by GC is $1.55: 1$ (Supplementary Fig. S4). This may be resulted from the small outcoming of $\mathrm{CO}_{2}$ from $\mathrm{NaHCO}_{3}$, the product of reaction (3), in the present acid solution (with the initial $\mathrm{pH}$ value of 3.65$)^{33}$. Based on the volume of $\mathrm{H}_{2}$, the total conversion (Supplementary Eq. S1) can reach 85\% within $160 \mathrm{~min}$. Furthermore, the turnover frequency (TOF) is calculated (Supplementary Eq. S2) to be $64 \mathrm{~mol} \mathrm{H}_{2} \mathrm{~mol}^{-1}$ catalyst h${ }^{-1}$ at $298 \mathrm{~K}$. This excellent conversion and TOF values are the highest one ever reported in FA/SF system at room temperature, and even comparable to those at the elevated temperature (Supplementary Table $\mathrm{S} 1)^{23,26-28}$. It is noteworthy that, the molar ratio of FA to SF has an obvious effect to the performance of the resulted $\mathrm{Pd} / \mathrm{C}$ catalyst. Whether increase or decrease the mole percent of FA from the present value of $56 \%$ to others $(0 \%, 25 \%, 75 \%$, and $100 \%)$, the activity of $\mathrm{Pd} / \mathrm{C}$ is decreased (Supplementary Fig. S7). Typically, pure FA generates no gas at all due to the non-formation of Pd NPs with only FA (Supplementary Fig. S1). On the other hand, pure SF liberates the pure $\mathrm{H}_{2}$ gas (Supplementary Fig. S8), which agrees well with the equation (3). 


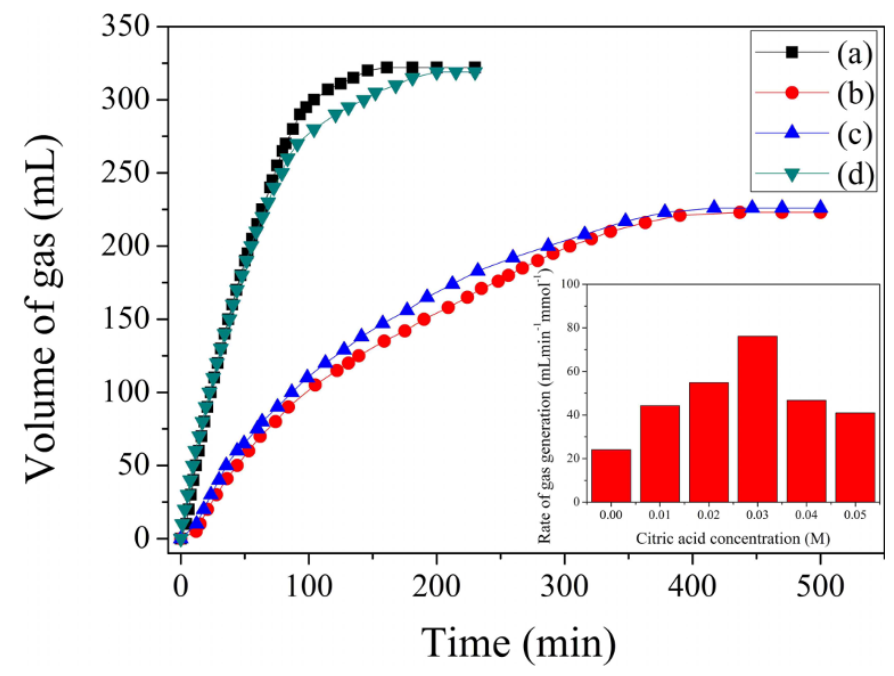

Figure $2 \mid$ Catalytic activities of different $\mathrm{Pd} / \mathrm{C}$. Gas generation by decomposition of FA/SF (1.06 M/0.84 M, $5 \mathrm{~mL}$ ) catalyzed by Pd/C synthesized $\left(\mathrm{n}_{\mathrm{Pd}} / \mathrm{n}_{(\mathrm{FA}+\mathrm{SF})}=0.005\right)$ (a) with citric acid added initially, (b) without citric acid, (c) with citric acid added after $40 \mathrm{~min}$ of the reaction, and (d) with citric acid after washing at $298 \mathrm{~K}$. Inset: rates of gas generation from FA/SF $(1.06 \mathrm{M} / 0.84 \mathrm{M}, 5 \mathrm{~mL})$ over Pd/C $\left(\mathrm{n}_{\mathrm{Pd}} / \mathrm{n}_{(\mathrm{FA}+\mathrm{SF})}=0.005\right)$ synthesized in different concentrations of citric acid at $298 \mathrm{~K}$.

With the absence of citric acid in the system, $\mathrm{Pd} / \mathrm{C}$ shows a very poor activity, and only $223 \mathrm{~mL}$ of gas is finally obtained even after 440 minutes (Fig. 2b), corresponding to a conversion of about $59 \%$. The TOF is only $16.1 \mathrm{~mol} \mathrm{H}_{2} \mathrm{~mol}^{-1}$ catalyst $\mathrm{h}^{-1}$, which is exactly onefourth of that catalyzed by $\mathrm{Pd} / \mathrm{C}$ with citric acid. Based on the above results, it is reasonably to believe that citric acid is indispensable to the high catalytic performance of the in situ prepared $\mathrm{Pd} / \mathrm{C}$ for $\mathrm{H}_{2}$ generation from FA/SF at room temperature.

To identify what kind of effect that citric acid plays on the dramatic enhancement in activity of $\mathrm{Pd} / \mathrm{C}$, the same catalytic reaction is applied by adding citric acid after the reaction begins for $40 \mathrm{~min}$, which means that citric acid is nonexistent during the nucleation and growth of Pd NPs. As a consequence, no enhancement in terms of activity has been observed at all (Fig. 2c). Moreover, after $\mathrm{Pd} / \mathrm{C}$ catalyst synthesized with citric acid is washed by water to remove the citric acid, it shows the similar high activity as that without washing (Fig. 2a, d). Therefore, citric acid has no strong interaction with Pd NPs to acts as a co-catalyst for decomposition of FA/SF but plays a key role in Pd NPs during their nucleation and growth processes, which thus leads to the obvious enhancement in catalytic activity of $\mathrm{Pd} / \mathrm{C}$ at room temperature.

To further determine the influence of citric acid on the catalytic performance of $\mathrm{Pd} / \mathrm{C}$, the decomposition is also applied over $\mathrm{Pd} / \mathrm{C}$ catalyst prepared in various concentrations of citric acid solution (Fig. 2 inset). Obviously, the activity of $\mathrm{Pd} / \mathrm{C}$ increases with the increasing concentration of citric acid up to $0.03 \mathrm{M}$. However, further increase of the citric acid concentration brings out the decrease of the activity, which may be accounted for the over occupation of the active sites of Pd NPs by citric acid ${ }^{38}$.

Additionally, the temperature dependence of activity for the best $\mathrm{Pd} / \mathrm{C}$ catalyst with citric acid has also been studied (Fig. 3). It can be seen clearly that the activity of $\mathrm{Pd} / \mathrm{C}$ is enhanced greatly with the increasing temperature. The reaction time can be shortened from 160 to $49 \mathrm{~min}$ when the temperature is increased from 298 to $318 \mathrm{~K}$.

Characterizations of catalyst. The transmission electron microscopy (TEM) image of the in situ prepared catalyst with citric acid before reaction shows that the NPs are well-dispersed on carbon with an average particle size of $2.8 \mathrm{~nm}$ (Fig. 4a; Supplementary Fig. S9a).

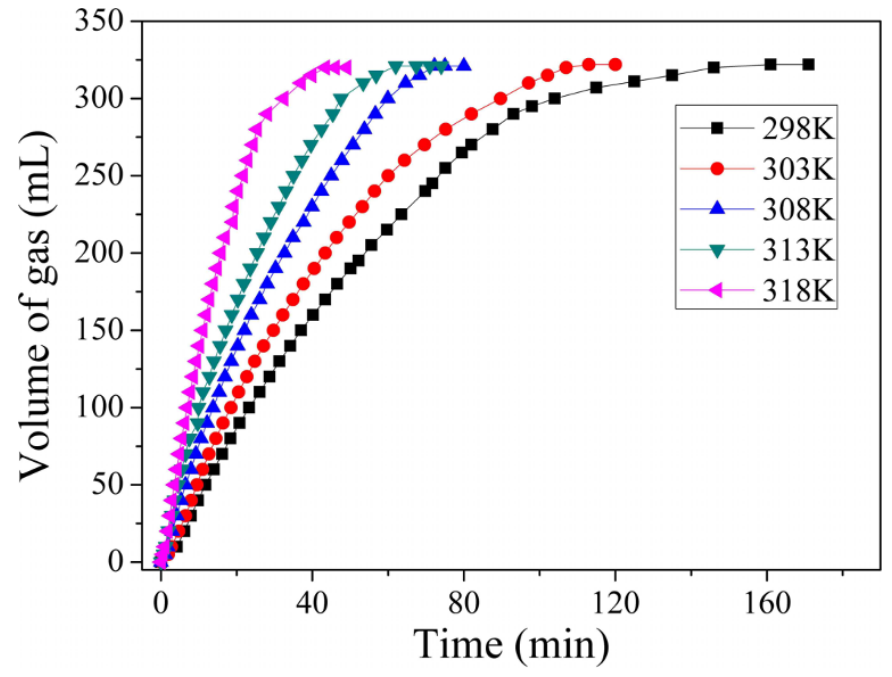

Figure $3 \mid$ Activities at different temperatures. Gas generation by decomposition of FA/SF (1.06 M/0.84 M, $5 \mathrm{~mL})$ over Pd/C synthesized with citric acid $\left(\mathrm{n}_{\mathrm{Pd}} / \mathrm{n}_{(\mathrm{FA}+\mathrm{SF})}=0.005\right)$ at different temperature.

The high resolution TEM (HRTEM) image of a single particle (Fig. 4b) reveals the metallic lattice fringes of face-centered cubic Pd (111) plane with the space of $0.224 \mathrm{~nm}$, which agrees well with its X-ray diffraction (XRD) result (Fig. $4 \mathrm{~d})^{39}$. In addition, the energydispersive X-ray (EDX) and X-ray photoelectron spectroscopy (XPS) results also support that Pd NPs have been successfully in situ synthesized (Fig. 4e, f). After the catalytic reaction, $\mathrm{Pd} / \mathrm{C}$ shows the similar crystal structure and average particle size as that before the reaction (Supplementary Fig. S10). In addition, the BET surface areas for $\mathrm{Pd} / \mathrm{C}$ before and after reaction are tested to be 169 and $178 \mathrm{~m}^{2} / \mathrm{g}$, respectively. Based on the above results, it is reliable to believe that the present $\mathrm{Pd} / \mathrm{C}$ has a good stability during the catalytic reaction.

Without citric acid, the obtained Pd NPs on carbon before reaction are severely aggregated with a larger average particle size of $11.2 \mathrm{~nm}$ (Fig. 4c; Supplementary Fig. S9b). Therefore, citric acid serves as an efficient dispersing agent during the formation of Pd NPs in the present system, which can be explained as follows: the three carboxyl anions of citric acid are strongly adsorbed on the surface of carbon at first ${ }^{40,41}$, and then attach $\mathrm{Pd}^{2+}$ by ion exchange or coordination reaction as the nucleation $\operatorname{sites}^{40}$; upon reduction by SF, due to the hydrophobic or coulombic effects on the Pd clusters ${ }^{42,43}$, citric acid can uniformly anchor the formed Pd NPs on carbon surface and control the sizes and distributions during the growth of NPs. However, citric acid, during the synthetic process, can not change the valence state of Pd NPs (Fig. 4f), which means that the interface of citric acid and Pd NPs has no strongly chemical interaction.

Recycle stability. Lifetime is very important for the practical application of nanocatalysts. In this sense, the recycle test of $\mathrm{Pd} / \mathrm{C}$ synthesized with citric acid has been applied for the same decomposing reaction (Fig. 5). It can be seen clearly that there is only a slight deactivation has been observed in the $2^{\text {nd }}$ run, which denotes the good stability of $\mathrm{Pd} / \mathrm{C}$ during the initial two runs. Unfortunately, the catalytic activity losses seriously in the $4^{\text {th }}$ run (Supplementary Fig. S11). Further investigations are needed to improve the durability of the present $\mathrm{Pd} / \mathrm{C}$ catalyst.

\section{Discussion}

The catalytic properties of the nanocatalysts usually depend on the sizes, morphologies, distributions, and surface states of $\mathrm{NPs}^{44-47}$. Generally, the smaller the particle size, the greater its surface area, which may benefit its activity ${ }^{48-50}$. However, NPs with ultrafine sizes are easily aggregated due to their high surface energy and thereby 

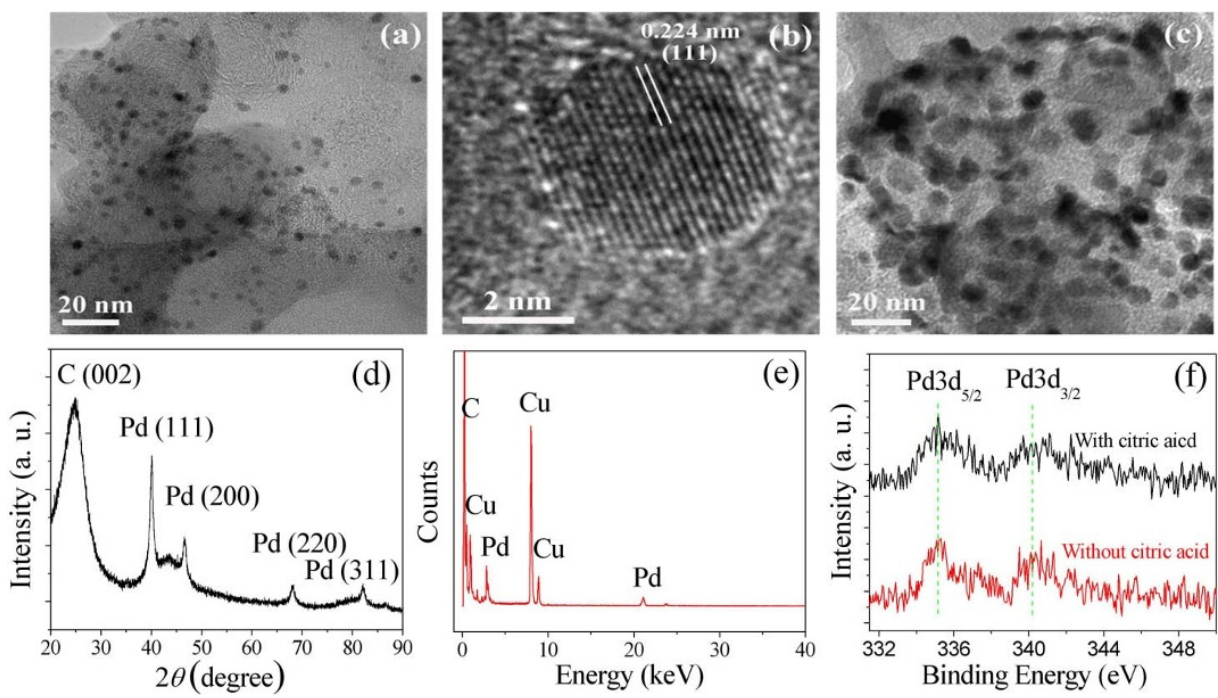

Figure $4 \mid$ Catalyst characterizations. (a) TEM image, (b) HRTEM image, (d) XRD pattern, and (e) EDX pattern of Pd/C synthesized with citric acid. (c) TEM image of Pd/C synthesized without citric acid. (f) XPS spectra of Pd element in Pd/C synthesized with and without citric acid.

induces low activites ${ }^{51-52}$. To avoid the aggregation, dispersing agents are usually employed to stabilize the $\mathrm{NPs}^{53-56}$. However, too strong affiliation of the agents to the surface of NPs may cause the severe deactivation of $\mathrm{NPs}^{55,57}$. In this sense, finding an appropriate dispersing agent for the target NPs is very important to reach the purpose of efficient reduction of the particle sizes, prevention of the aggregation, and enhancement of the catalytic activity of the NPs. Citric acid, which is used here as a dispersing agent, is more appropriate than other ones for modification of Pd NPs to catalyze the decomposition of FA/SF (Fig. 6). Replace citric acid by L-ascorbic acid $\left(\mathrm{C}_{6} \mathrm{H}_{8} \mathrm{O}_{6}\right)$, the resulted Pd NPs has a larger average particle size of $5.6 \mathrm{~nm}$ than that synthesized with citric acid (Supplementary Fig. S12), and exhibits a lower activity for the same reaction, where $250 \mathrm{~mL}$ of gas can be generated in $440 \mathrm{~min}$ (Fig. 6a). Replacing citric acid by polyvinylpyrrolidone (PVP, $\left.\left(\mathrm{C}_{6} \mathrm{H}_{9} \mathrm{NO}\right)_{\mathrm{n}}\right)$, Pd NPs get the smallest particle size of $2.3 \mathrm{~nm}$ (Supplementary Fig. S13), but exhibit the lowest activity for the reaction (Fig. 6b, $25 \mathrm{~mL}, 440 \mathrm{~min}$ ). The above results can be understand as follows: L-ascorbic acid, which has a similar molecule size as citric acid, has a weaker function to $\mathrm{Pd}^{2+}$ than citric acid ${ }^{39}$, and causes formation of the bigger Pd NPs and thus the lower activity of

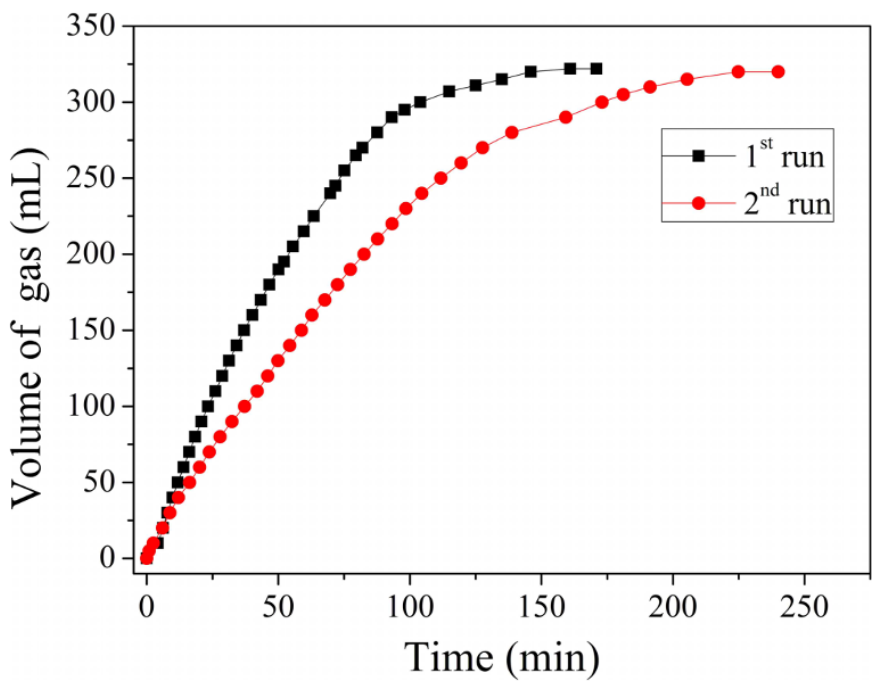

Figure 5 | Recycle stability. Recycle test of Pd/C synthesized with citric acid toward $\mathrm{H}_{2}$ generation from FA/SF at the $1^{\text {st }}$ and $2^{\text {nd }}$ runs.
Pd NPs. However, PVP, a huge molecule resulting in the formation of the smallest particle size, occupies much of the active sites of Pd NPs, and severely deactivates the catalyst. This has been confirmed by the fact that, after washing off the PVP, Pd/C shows a dramatic enhancement in its activity, which is even comparable to that synthesized with citric acid (Supplementary Fig. S14). Citric acid has a moderate binding to the surface of noble metal $\mathrm{NPs}^{39}$, and thereby efficiently leads to the formation of the small and well dispersed Pd NPs but does not block FA/SF adsorption and decomposition.

In summary, a very facile strategy has been successfully applied for highly efficient $\mathrm{H}_{2}$ generation from FA/SF through a heterogeneous catalytic reaction over in situ synthesized $\mathrm{Pd} / \mathrm{C}$ catalyst in the presence of citric acid. The present monometallic catalyst synthesized with citric acid exhibits the high catalytic activity, selectivity and durability for decomposition of FA/SF at room temperature. This simple but very effective monometallic catalyst is believed to strongly promote the practical applications of FA/SF as a CO-free $\mathrm{H}_{2}$ generation system for fuel cell applications.

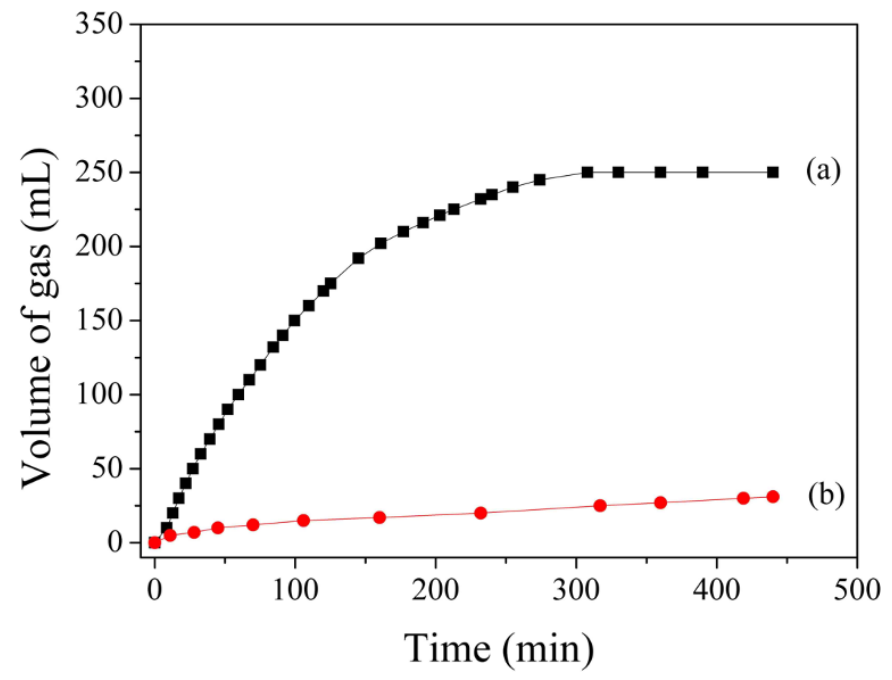

Figure 6 | Effect of different dispersing agents. Gas generation by decomposition of FA/SF $(1.06 \mathrm{M} / 0.84 \mathrm{M}, 5 \mathrm{~mL})$ catalyzed by in situ prepared $\mathrm{Pd} / \mathrm{C}\left(\mathrm{n}_{\mathrm{Pd}} / \mathrm{n}_{(\mathrm{FA}+\mathrm{SF})}=0.005\right)$ in the presence of $(\mathrm{a}) \mathrm{L}$-ascorbic acid and (b) PVP at $298 \mathrm{~K}$. 


\section{Methods}

Chemicals. Formic acid $\left(\mathrm{HCO}_{2} \mathrm{H}\right.$, Sigma-Aldrich, $\left.96 \%\right)$, sodium tetrachloropalladate $\left(\mathrm{Na}_{2} \mathrm{PdCl}_{4}\right.$, Sinopharm Chemical Reagent Co., Ltd, $\left.36.4 \%\right)$, sodium formate dehydrate $\left(\mathrm{HCO}_{2} \mathrm{Na} \cdot 2 \mathrm{H}_{2} \mathrm{O}\right.$, Sinopharm Chemical Reagent Co., Ltd, $\left.>99.5 \%\right)$, citric acid monohydrate $\left(\mathrm{C}_{6} \mathrm{H}_{8} \mathrm{O}_{7} \cdot \mathrm{H}_{2} \mathrm{O}\right.$, Beijing Chemicals Works, $\left.>99.5 \%\right)$, L-ascorbic acid $\left(\mathrm{C}_{6} \mathrm{H}_{8} \mathrm{O}_{6}\right.$, Sinopharm Chemical Reagent Co., Ltd, >99.7\%), aqueous hydrochloric acid ( $\mathrm{HCl}$, Beijing Chemicals Works, $>35.0 \%$ ), polyvinylpyrrolidone K30 (PVP, $\left(\mathrm{C}_{6} \mathrm{H}_{9} \mathrm{NO}\right)_{n}, \mathrm{Mw}$ : av. 58000, Beijing Chemicals Works), acetic acid $\left(\mathrm{CH}_{3} \mathrm{CO}_{2} \mathrm{H}, 36 \sim 37 \%\right.$, Beijing Chemicals Works), tetrahydrofuran $\left(\mathrm{C}_{4} \mathrm{H}_{8} \mathrm{O}\right.$, THF, 99.9\%, Sinopharm Chemical Reagent Co., Ltd,) and Vulcan XC-72 carbon (C, Sinopharm Chemical Reagent Co., Ltd) were used without further purification. Deionized water with the specific resistance of $18.2 \mathrm{M} \Omega \cdot \mathrm{cm}$ was obtained by reversed osmosis followed by ion-exchange and filtration.

Physical characterization. Powder X-ray diffraction (XRD) was performed on a Rigaku RINT-2000 X-ray diffractometer with $\mathrm{Cu} \mathrm{K \alpha}$. Transmission electron microscope (TEM, Tecnai F20, Philips) and corresponding energy-dispersive X-ray (EDX) were applied for the detailed microstructure and composition analyses. Surface Area was determined by BET measurements using an Autosorb-1 Surface Area Analyzers (Quantachrome Instrument Corporation). X-ray photoelectron spectrometry (XPS) analysis was carried out on an ESCALABMKLL X-ray photoelectron spectrometer using an $\mathrm{Al} \mathrm{K} \alpha$ source.

Mass spectrometry (MS) analysis of the generated gases was performed on an OmniStar GSD320 mass spectrometer. Detailed information for $\mathrm{CO}_{2}, \mathrm{H}_{2}$ and $\mathrm{CO}$ was performed on GC-7900 with thermal conductivity detector (TCD) and flame ionization detector (FID)-methanator (FID, detection limit: $\sim 10 \mathrm{ppm}$ for CO). UV-Vis absorption spectra were recorded on an Agilent Cary 50 spectrophotometer in the wavelength range of $350-600 \mathrm{~nm}$.

$\mathrm{H}_{\mathbf{2}}$ generation from $\mathrm{FA} / \mathrm{SF}$ over $\mathrm{Pd} / \mathrm{C}$ synthesized with citric acid. Typically, $10.0 \mathrm{~mL}$ of $\mathrm{Na}_{2} \mathrm{PdCl}_{4}\left(4.7 \times 10^{-3} \mathrm{M}\right)$ aqueous solution containing $95.0 \mathrm{mg}$ of Vulcan XC-72 carbon was kept in a two-necked round-bottom flask. One neck was connected to a gas burette, and the other was connected to a pressure-equalization funnel to introduce $5.0 \mathrm{~mL}$ of the mixed aqueous solution containing FA (1.06 M), SF ( $0.84 \mathrm{M})$ and citric acid $(0.03 \mathrm{M})$. The reaction begins once the mixed aqueous solution was added into the $\mathrm{Na}_{2} \mathrm{PdCl}_{4}$ solution with magnetic stirring $(600 \mathrm{r} / \mathrm{min})$. The evolution of gas was monitored using a gas burette. The reactions were carried out under argon $(\mathrm{Ar})$ and ambient atmosphere at different temperatures. Moreover, the similar reactions with different FA mole percents in FA/SF $(0 \%, 25 \%, 56 \%, 75 \%, 100 \%)$ were also applied under ambient atmosphere at $298 \mathrm{~K}$, where the total mole number of FA and SF was kept as $9.5 \mathrm{mmol}$, and the molar ratio of Pd:(FA+SF) was 0.005 .

For comparison, FA/SF decomposing reaction catalyzed by in situ prepared Pd/C without citric acid and with L-ascorbic acid, PVP have also been carried out under the similar experimental conditions. In addition, after $\mathrm{Pd} / \mathrm{C}$ catalyst was formed in the presence of citric acid, it was separated and washed by water for several times. And then, the washed $\mathrm{Pd} / \mathrm{C}$ was used for the same FA/SF decomposing reaction. Such washing and decomposing experiments were also carried on $\mathrm{Pd} / \mathrm{C}$ synthesized in PVP. However, the washing solvent for PVP is acetic acid and water.

Moreover, the similar FA/SF decomposition has also been applied in pure THF over in situ prepared $\mathrm{Pd} / \mathrm{C}$ with citric acid at $298 \mathrm{~K}$.

Recycle test of Pd/C synthesized with citric acid. After the decomposition of FA/SF was completed, the in situ synthesized $\mathrm{Pd} / \mathrm{C}$ with citric acid was separated from the reaction solution by centrifugation and washed by water for several times. The washed $\mathrm{Pd} / \mathrm{C}$ was then re-dispersed in $10 \mathrm{~mL}$ of water in a flask, and the new aqueous solution $(5.0 \mathrm{~mL})$ containing FA $(1.06 \mathrm{M})$ and $\mathrm{SF}(0.84 \mathrm{M})$ was added into the flask with magnetic stirring $(600 \mathrm{r} / \mathrm{min})$ to begin the recycle test of $\mathrm{Pd} / \mathrm{C}$. The evolution of gas was monitored using a gas burette. Such recycle tests were repeated for 4 times.

1. Schlapbach, L. \& Züttel, A. Hydrogen-storage materials for mobile applications. Nature 414, 353-358 (2001).

2. Turner, J. A. Sustainable hydrogen production. Science 305, 972-974 (2004).

3. Rowsell, J. L. C. \& Yaghi, O. M. Strategies for hydrogen storage in metal-organic frameworks. Angew. Chem., Int. Ed 44, 4670-4679 (2005).

4. Fellay, C., Dyson, P. J. \& Laurenczy, G. A viable hydrogen-storage system based on selective formic acid decomposition with a ruthenium catalyst. Angew. Chem., Int. Ed 47, 3966-3968 (2008)

5. Liu, W., Zhao, Y. H., Li, Y., Jiang, Q. \& Lavernia, E. J. Enhanced hydrogen storage on Li-dispersed carbon nanotubes. J. Phys. Chem. C 113, 2028-2033 (2009).

6. Zhang, Z. W., Zheng, W. T. \& Jiang, Q. Hydrogen adsorption on Ce/BNNT system: A DFT study. Int. J. Hydrogen Energy 37, 5090-5099 (2012).

7. Johnson, T. C., Morris, D. J. \& Wills, M. Hydrogen generation from formic acid and alcohols using homogeneous catalysts. Chem. Soc. Rev. 39, 81-88 (2010).

8. Sascha, O. Ironing out hydrogen storage. Science 333, 1714-1715 (2011).

9. Nielsen, M. et al. Efficient hydrogen production from alcohols under mild reaction conditions. Angew. Chem., Int. Ed 50, 9593-9597 (2011).

10. Loges, B., Boddien, A., Gärtner, F., Junge, H. \& Beller, M. Catalytic generation of hydrogen from formic acid and its derivatives: useful hydrogen storage materials. Top. Catal 53, 902-914 (2010).
11. Jiang, H. L., Singh, S. K., Yan, J. M., Zhang, X. B. \& Xu, Q. Liquid-phase chemical hydrogen storage: catalytic hydrogen generation under ambient conditions. ChemSusChem 3, 541-549 (2010).

12. Enthaler, S., Langermann, J. v. \& Schmidt, T. Carbon dioxide and formic acid-the couple for environmental-friendly hydrogen storage? Energy Environ. Sci. 3, 1207-1217 (2010).

13. Hu, C., Ting, S. W., Tsui, J. \& Chan, K. Y. Formic acid dehydrogenation over $\mathrm{PtRuBiO}_{\mathrm{X}} / \mathrm{C}$ catalyst for generation of $\mathrm{CO}$-free hydrogen in a continuous-flow reactor. Int. J. Hydrogen Energy 37, 6372-6380 (2012).

14. Park, S., Xie, Y. \& Weaver, M. J. Electrocatalytic pathways on carbon-supported platinum nanoparticles: comparison of particle-size-dependent rates of methanol, formic acid, and formaldehyde electrooxidation. Langmuir 18 $5792-5798$ (2002).

15. Ji, X. et al. Nanaocrystalline intermetallics on mesoporous carbon for formic acid fuel cell anodes. Nature Chem. 2, 286-293 (2010).

16. Loges, B., Boddien, A., Junge, H. \& Beller, M. Controlled generation of hydrogen from formic acid amine adducts at room temperature and application in $\mathrm{H}_{2} / \mathrm{O}_{2}$ fuel cells. Angew. Chem. Int. Ed. 47, 3962-3965 (2008).

17. Fukuzumi, S., Kobayashi, T. \& Suenobu, T. Unusually large tunneling effect on highly efficient generation of hydrogen and hydrogen isotopes in $\mathrm{pH}$-selective decomposition of formic acid catalyzed by a heterodinuclear iridium-ruthenium complex in water. J. Am. Chem. Soc. 132, 1496-1497 (2010).

18. Boddien, A. et al. Iron-catalyzed hydrogen production from formic acid. J. Am. Chem. Soc. 132, 8924-8934 (2010).

19. Boddien, A. et al. Efficient dehydrogenation of formic acid using an iron catalyst. Science 333, 1733-1736 (2011).

20. Boddien, A. \& Junge, H. Acidic ideas for hydrogen storage. Nature nanotech. 6 , 265-266 (2011)

21. Ruthven, D. M. \& Upadhye, R. S. The catalytic decomposition of aqueous formic acid over suspended palladium catalysts. J. Catal. 21, 39-47 (1971).

22. Hill, S. P. \& Winterbottom, J. M. The conversion of polysaccharides to hydrogen gas. Part I: The palladium catalysed decomposition of formic acid/ sodium formate solutions. J. Chem. Technol. Biotechnol. 41, 121-133 (1988).

23. Zhou, X. C. et al. High-quality hydrogen from the catalyzed decomposition of formic acid by Pd-Au/C and Pd-Ag/C. Chem. Commun. 3540-3542 (2008).

24. Ojeda, M. \& Iglesia, E. Formic acid dehydrogenation on Au-based catalysts at near-ambient temperatures. Angew. Chem. Int. Ed. 48, 4800-4803 (2009).

25. Ting, S. W., Cheng, S., Tsang, K. Y., Laak, N. v. d. \& Chan, K. Y. Low activation energy dehydrogenation of aqueous formic acid on platinum-ruthenium-bismuth oxide at near ambient temperature and pressure. Chem. Commun. 7333-7335 (2009).

26. Huang, Y., Zhou, X., Yin, M., Liu, C. \& Xing, W. Novel PdAu@Au/C core-shell catalyst: superior activity and selectivity in formic acid decomposition for hydrogen generation Chem. Mater. 22, 5122-5128 (2010).

27. Tedsree, K. et al. Hydrogen production from formic acid decomposition at room temperature using a Ag-Pd core-shell nanocatalyst. Nature nanotech. 6, 302-307 (2011).

28. Gu, X., Lu, Z. H., Jiang, H. L., Akita, T. \& Xu, Q. Synergistic catalysis of metalorganic framework-immobilized Au-Pd nanoparticles in dehydrogenation of formic acid for chemical hydrogen storage. J. Am. Chem. Soc. 133, 11822-11825 (2011).

29. Bi, Q. Y. et al. Efficient subnanometric gold-catalyzed hydrogen generation via formic acid decomposition under ambient conditions. J. Am. Chem. Soc. 134, 8926-8933 (2012).

30. Yadav, M., Akita, T., Tsumori, N. \& Xu, Q. Strong metal-molecular support interaction (SMMSI): amine-functionalized gold nanoparticles encapsulated in silica nanospheres highly active for catalytic decomposition of formic acid. J. Mater. Chem. 22, 12582-12586 (2012).

31. Zhou, X. et al. Available hydrogen from formic acid decomposition by rare earth elements promoted $\mathrm{Pd}-\mathrm{Au} / \mathrm{C}$ catalysts at low temperature. ChemSusChem 3, 1379-1382 (2010).

32. Bulushev, D. A., Jia, L., Beloshapkin, S. \& Ross, J. R. H. Improved hydrogen production from formic acid on a Pd/C catalyst doped by potassium. Chem. Commun. 48, 4184-4186 (2012).

33. Boddien, A. et al. $\mathrm{CO}_{2}$ " "neutral" hydrogen storage based on bicarbonates and formats.Angew. Chem. Int. Ed. 50, 6411-6414 (2011).

34. Guo, S., Dong, S. \& Wang, E. Three-dimensional Pt-on-Pd bimetallic nanodendrites supported on grapheme nanosheet: facile synthesis and used as an advanced nanoelectrocatalyst for methanol oxidation. ACS Nano 4, 547-555 (2010).

35. Kordesch, K. V. \& Simader, G. R. Environmental impact of fuel cell technology. Chem. Rev. 95, 191-207 (1995).

36. Wiener, H., Sasson, Y. \& Blum, J. Palladium-catalyzed decomposition of aqueous alkali metal formate solutions. J. Mol. Catal. 35, 277-284 (1986).

37. Joo, S. H. et al. Thermally stable Pt/mesoporous silica core-shell nanocatalysts for high-temperature reactions. Nature Mater. 8, 126-131 (2009).

38. Greeley, J., Jaramillo, T. F., Bonde, J., Chorkendorff, I. \& Nørskov, J. K. Computational high-throughput screening of electrocatalytic materials for hydrogen evolution. Nature Mater. 5, 909-913 (2006).

39. Xiong, Y., McLellan, J. M., Yin, Y. \& Xia, Y. Synthesis of palladium icosahedra with twinned structure by blocking oxidative etching with citric acid or citrate ions. Angew. Chem. Int. Ed. 46, 790-794 (2007). 
40. Yu, R. Q. et al. Platinum deposition on carbon nanotubes via chemical modification. Chem. Mater. 10, 718-722 (1998).

41. Chen, J. P., Wu, S. \& Chong, K. H. Surface modification of a granular activated carbon by citric acid for enhancement of copper adsorption. Carbon 41, 19791986 (2003).

42. Henglein, A. Formation of colloidal silver nanoparticles: capping action of citrate. J. Phys. Chem. B 103, 9533-9539 (1999).

43. Guo, J. W., Zhao, T. S., Prabhuram, J. \& Wong, C. W. Preparation and the physical/electrochemical properties of a $\mathrm{Pt} / \mathrm{C}$ nanocatalyst stabilized by citric acid for polymer electrolyte fuel cells. Electrochim. Acta 50, 1973-1983 (2005).

44. Perez-Alonso, F. J. et al. The effect of size on the oxygen electroreduction activity of mass-selected platinum nanoparticles. Angew. Chem., Int. Ed. 51, 4641-4643 (2012).

45. Zhang, H. et al. Facile synthesis of Pd-Pt alloy nanocages and their enhanced performance for preferential oxidation of CO in excess hydrogen. ACS Nano 5 , 8212-8222 (2011).

46. Shao, M., Peles, A. \& Shoemaker, K. Electrocatalysis on platinum nanoparticles: particle size effect on oxygen reduction reaction activity. Nano Lett. 11, 3714-3719 (2011).

47. Li, P. Z., Aijaz, A. \& Xu, Q. Highly dispersed surfactant-free nickel nanoparticles and their remarkable catalytic activity in the hydrolysis of ammonia borane for hydrogen generation. Angew. Chem., Int. Ed. 51, 6753-6756 (2012).

48. He, L. et al. A noble-metal-free catalyst derived from Ni-Al hydrotalcite for hydrogen generation from $\mathrm{N}_{2} \mathrm{H}_{4} \cdot \mathrm{H}_{2} \mathrm{O}$ decomposition. Angew. Chem. 124, 6295-6298 (2012).

49. Singh, S. K., Zhang, X. B. \& Xu, Q. Room-temperature hydrogen generation from hydrous hydrazine for chemical hydrogen storage. J. Am. Chem. Soc. 131, 9894-9895 (2009).

50. Burda, C., Chen, X., Narayanan, R. \& EI-Sayed, M. A. Chemistry and properties of nanacrystals of different shapes. Chem. Rev 105, 1025-1102 (2005).

51. White, R. J., Luque, R., Budarin, V. L., Clark, J. H. \& Macquarrie, J. Supported metal nanoparticles on porous materials: methods and application. Chem. Soc Rev. 38, 481-494 (2009).

52. Astruc, D., Lu, F. \& Aranzaes, J. R. Nanoparticles as recyclable catalysts: the frontier between homogeneous and heterogeneous catalysis. Angew. Chem., Int. Ed. 44, 7852-7872 (2005).

53. Pileni, M. P. The role of soft colloidal templates in controlling the size and shape of inorganic nanocrystals. Nat. Mater. 2, 145-150 (2003).
54. Gugliotti, L. A., Feldheim, D. L. \& Eaton, B. RNA-mediated metal-metal bond formation in the synthesis of hexagonal palladium nanoparticles. Science 304, 850-852 (2004).

55. Mazumder, V. \& Sun, S. Oleylamine-mediated synthesis of Pd nanoparticles for catalytic formic acid oxidation. J. Am. Chem. Soc. 131, 4588-4589 (2009).

56. Jin, M., Zhang, H., Xie, Z. \& Xia, Y. Palladium nanocrystals enclosed by $\{100\}$ and $\{111\}$ facets in controlled proportions and their catalytic activities for formic acid oxidation. Energy Environ. Sci. 5, 6352-6357 (2012).

57. Chen, X., Wu, G., Chen, J., Chen, X., Xie, Z. \& Wang, X. Synthesis of "clean" and well-dispersive $\mathrm{Pd}$ nanoparticles with excellent electrocatalytic property on graphene oxide. J. Am. Chem. Soc. 133, 3693-3695 (2011).

\section{Acknowledgments}

This work is supported in part by National Key Basic Research, Development Program (2010CB631001), National Natural Science Foundation of China (51101070), Program for Changjiang Scholars and Innovative Research Team in University, Program for New Century Excellent Talents in University of the Ministry of Education of China (NCET-09-0431); Jilin Province Science and Technology Development Program (201101061); and Jilin University Fundamental Research Funds.

\section{Author contributions}

W.Z.L., Y.J.M., and J.Q. designed the experiments, analyzed the data, and wrote the paper; W.Z.L., W.H.L., and P.Y. carried out the experiments; Y.J.M., and J.Q. supervised the project.

\section{Additional information}

Supplementary information accompanies this paper at http://www.nature.com/ scientificreports

Competing financial interests: The authors declare no competing financial interests.

License: This work is licensed under a Creative Commons Attribution-NonCommercial-No Derivate Works 3.0 Unported License. To view a copy of this license, visit http://creativecommons.org/licenses/by-nc-nd/3.0/

How to cite this article: Wang, Z., Yan, J., Wang, H., Ping, Y. \& Jiang, Q. Pd/C Synthesized with Citric Acid: An Efficient Catalyst for Hydrogen Generation from Formic Acid/Sodium Formate. Sci. Rep. 2, 598; DOI:10.1038/srep00598 (2012). 